\title{
The resilience of postglacial hunter-gatherers to abrupt climate change
}

Simon Blockley ${ }^{\mathrm{a}^{*}}$, Ian Candy ${ }^{\mathrm{a}}$, Ian Matthews ${ }^{\mathrm{a}}$, Pete Langdon ${ }^{\mathrm{b}}$, Cath Langdon ${ }^{\mathrm{b}}$, Adrian Palmer $^{\mathrm{a}}$, Paul Lincoln ${ }^{\mathrm{a}}$, Ashley Abrook ${ }^{\mathrm{a}}$, Barry Taylor ${ }^{\mathrm{c}}$, Chantal Conneller ${ }^{\mathrm{d}}$, Alex Bayliss ${ }^{\mathrm{e}}$, Alison MacLeod ${ }^{\mathrm{f}}$, Laura Deeprose ${ }^{\mathrm{g}}$, Chris Darvill ${ }^{\mathrm{h}}$, Rebecca Kearney ${ }^{\mathrm{i}}$, Nancy Beavan ${ }^{\mathrm{j}}$, Richard Staff ${ }^{\mathrm{ikj}}$, Michael Bamforth ${ }^{1}$, Maisie Taylor ${ }^{1}$, Nicky Milner'.

${ }^{a}$ Royal Holloway, Centre for Quaternary Research, Department of Geography, University of London, Egham, Surrey, TW20 0EX, UK

${ }^{\mathrm{b}}$ Geography and Environment, University of Southampton, University Road, Southampton, SO17 1BJ, UK

${ }^{\mathrm{c}}$ History and Archaeology, University of Chester, Parkgate Road, Chester, CH1 4BJ, UK

${ }^{\mathrm{d} D}$ Department of Archaeology, The University of Manchester, Oxford Rd, Manchester, M13 9PL, UK

${ }^{\mathrm{e}}$ Cannon Bridge House, 25 Dowgate Hill, London, EC4R 2YA and University of Stirling, FK9 4LA, UK

${ }^{\mathrm{f}}$ Department of Geography and Environmental Science, University of Reading, RG6 6D.W

${ }^{\mathrm{g}}$ Lancaster Environment Centre, Lancaster University, Lancaster, LA1 4YQ, UK

${ }^{\mathrm{h} D e p a r t m e n t ~ o f ~ G e o g r a p h y, ~ U n i v e r s i t y ~ o f ~ M a n c h e s t e r, ~ M a n c h e s t e r, ~ M 13 ~ 9 P L, ~ U K ~}$

${ }^{\mathrm{i}}$ Research Laboratory for Archaeology and the History of Art, University of Oxford, Oxford, OX1 2PG, UK

${ }^{\mathrm{j}}$ Institute of Environmental Science and Research, Keneperu Science Center, Wellington 5022, New Zealand

${ }^{\mathrm{k}}$ SUERC, University of Glasgow, Rankine Avenue, East Kilbride, G75 0QF UK

${ }^{1}$ Department of Archaeology, The King's Manor, University of York, York, YO1 7EP, UK

* Simon Blockley, Royal Holloway, Centre for Quaternary Research, Department of Geography, University of London, Egham, Surrey, TW20 0EX, UK 00441784 443405, Simon.Blockley@ rhul.ac.uk. https://orcid.org/0000-0003-0712-2118

Accepted for publication in Nature Ecology \& Evolution published by Springer Nature. Article is available at: https://doi.org/10.1038/s41559-018-0508-4 


\section{Abstract}

Understanding the resilience of early societies to climate change is an essential part of exploring the environmental sensitivity of human populations. There is significant interest in the role of abrupt climate events as a driver of early Holocene human activity, but there are very few well-dated records directly compared to local climate archives. Here we present evidence from the internationally important Mesolithic site of Star Carr showing occupation during the early Holocene, which is directly compared to a high-resolution palaeoclimate record from neighbouring lake beds. We show that once established there was intensive human activity at the site for several hundred years when the community was subject to multiple, severe, abrupt climate events that impacted air temperatures, the landscape and ecosystem of the region. However, these new results show that occupation and activity at the site persisted regardless of the environmental stresses experienced by this society. The Star Carr population displayed a high-level of resilience to climate change, suggesting that postglacial populations were not necessarily held hostage to the flickering switch of climate change. Instead we show that local, intrinsic changes in the wetland environment were more significant in determining human activity than the large-scale abrupt Early Holocene climate events.

The response of prehistoric societies to abrupt climate change is fundamental to our understanding of the resilience of early populations to environmental drivers ${ }^{1,2,3,4,5,6,7,8,9,10}$. Rapid changes in temperature and precipitation, and their concomitant impact on landscape and ecosystems, have been argued to lead to adaptations within early societies or, in extreme cases, the abandonment of a region ${ }^{7,8}$.

In this respect the early part of the Holocene was a key time interval. This period was characterized by numerous Abrupt Climatic Events (ACEs, defined here as centennial-scale abrupt climatic oscillations), triggered by ice-ocean interaction during the final wastage of northern hemisphere ice sheets ${ }^{11,12}$, and was critical to the postglacial recolonization of northern Europe. Of these ACEs, the impact of the $8.2 \mathrm{ka}$ event has been most frequently discussed $^{2,3,6,7,8,9,10}$ because the evidence indicates that northwestern Europe was widely populated by this time. Whilst some studies have argued that hunter-gatherer communities showed resilience to the $8.2 \mathrm{ka}^{\text {event }}{ }^{1,5,9}$, other work suggests these societies were highly susceptible to rapid climate forcing ${ }^{7,8,10}$. In particular it has been argued that this climatic event may have caused a crash in Mesolithic populations in Northern Britain ${ }^{7,8}$ and it has also been linked with changes in the Irish Mesolithic ${ }^{10}$. Consequently, sensitivity of these huntergatherer societies to environmental change and their resilience to ACEs continues to be debated.

Other ACEs are known from the early Holocene (e.g. the pre-Boreal oscillation, 11.1 and 9.3 ka events), but there are comparatively few well-dated archaeological sites of this time period. The impact on populations of these ACEs is therefore poorly understood. These societies did not simply occupy northwest Europe but were the earliest populations to attempt 
1 to recolonise this region after the last glacial, against a backdrop of some of the most extreme 2 ACEs known from the Holocene. Whether these populations were resilient to such events or 3 were susceptible to the environmental changes that they triggered is crucial to understanding

6 Resolving the effects of ACEs on early Holocene communities is problematic for two 7 reasons. The first relates to problems of producing high-resolution chronologies for 8 archaeological sites that can be directly compared with climatic events that may last only 100 9 years $^{13}$. The second is that most archaeological studies directly compare human activity to either local environmental archives (i.e. pollen), which may not conclusively record climatic change, or the Greenland ice cores. With respect to the former, it has been argued that some episodes of tree population decline in Britain during the early Holocene relate to anthropogenic burning rather than climatic cooling ${ }^{14}$. Additionally, whilst the Greenland ice cores contain clear expressions of $\mathrm{ACEs}^{15}$, this assumes that the climate forcing that triggers an effect recorded in Greenland also forces significant changes in climates and different environments of NW Europe. Studies of single sites with high-precision chronologies for human activity that are directly compared to detailed palaeoclimate records from the same location are extremely rare and yet it is this approach that is essential for investigating the effects of ACEs on early societies.

This study adopts such an approach in order to examine the resilience of early populations to ACEs. It is based on a detailed re-investigations of the early Holocene site of Star Carr; an internationally-renowned Early Mesolithic site where a large assemblage of material culture and faunal remains has been recovered from a stratified sequence of wetland deposits accumulating at the edge of an extensive former lake basin (Palaeolake Flixton) in the Vale of Pickering 16,17,18,19,20,21,22 (Figure 1). This site has produced one of the largest Mesolithic organic assemblages in Europe, the oldest evidence of carpentry in Europe in the form of large wooden platforms, rare artefacts such as red deer antler headdresses/masks ${ }^{23}$ (Figure 2), and the earliest evidence for built structures in Britain ${ }^{18}$. Our analysis integrates this record through a high-resolution archaeological chronology coupled with a multi-proxy palaeoclimate record.

\section{Results - Re-investigation of the Palaeolake Flixton archaeology and landscape}

\section{Archaeological evidence}

The Bayesian age model for occupation at Star Carr (Methods) and a summary of the site chronology are presented in Figures 3 and 4. The highest posterity density intervals for key parameters are given in Supplementary Table 2.

The archaeological record includes the construction of 'house' structures, timber platforms/trackways, economic activity, and more ritualized practices of deposition (Supplementary Figure 1). Evidence of this kind is extremely rare within the record for Northern Europe at this time and the site is unique within a British context. Some of the 
accumulation of brushwood (Supplementary Figure 2). Broadly contemporary with this is the detrital wood scatter; a large, sub-linear arrangement of worked wood, laid down to stabilize the soft basal deposits (Supplementary Figure 3). Within this, animal bone and a range of artefacts were deposited. Occupation of the dryland also occurred at this time, represented by a circular structure (central dryland structure); the earliest known 'house' structure in the British Isles. In the following centuries a series of large timber platforms were laid down within the lake-edge wetlands (Supplementary Figures 2 and 4) and large quantities of faunal remains, antler headdresses/masks, and organic and stone artefacts were deposited into the lake edge, whilst further structures were constructed on the dryland (Supplementary Figure 1). Occupation then became more episodic, with activity focusing on the edges of the wetlands. These changes in human activity occurred against the progressive evolution of the lake edge setting with a species-rich reedswamp environment forming in standing water gradually becoming shallower and boggier before being succeeded by more terrestrial fen and carr (Supplementary Figure 7).

\section{Palaeoclimates of the Palaeolake Flixton}

The deepest parts of the Palaeolake basin contains sediments spanning the period from the late Dimlington stadial to the final transition of wetland from an open water body to peatland, early in the Holocene ${ }^{21}$. To assess the interval represented by human occupation in the region, a composite palaeoenvironmental record was constructed by combining data from two cores that contained the best record of the Younger Dryas (Core C) and the earliest Holocene (Core $B)^{21}$. The age model was based on tephrochronology, radiocarbon dating and was integrated with archaeological chronology (Methods and Supplementary sections 6 and 7).

The palaeoclimate record contains evidence for two ACEs in the early Holocene (ACE $1=$ the older, and ACE 2 = the younger). These are defined by a) cooling recorded in both chironomid-inferred temperature reconstructions (C-IT) and $\delta^{18} \mathrm{O}$ values, b) a centennialscale duration and c) a response in the local environment recorded in the vegetation assemblage (Supplementary data $4 \& 5$; Supplementary Figures 6-12). As such they exhibit all of the features of early Holocene climate oscillations as expressed in the British record $^{12,26,27}$. ACE 1 is most strongly seen in the $\delta^{18} \mathrm{O}$ signal (decline by $\sim 4 \%$ ) along with a $1.5^{\circ} \mathrm{C}$ decline in C-IT summer temperatures. ACE 2 is clearly expressed in both the $\delta^{18} \mathrm{O}$ signal (decline by $\sim 1.5 \%$ ) and the C-IT record (decline by $\sim 1.5^{\circ} \mathrm{C}$ ). Although the C-IT shifts associated with ACE 1 and 2 are only just greater than the resolution of the technique, they are considered valid as they occur in association with well-defined isotopic shifts (Supplementary Figures 4 and 6). ACE 1 is coincident with the 11.4 ka event recorded in the Greenland ice $\operatorname{cores}^{28}$, whilst ACE 2 is coincident with an event at 11.1 ka recorded in NGRIP (but not in GRIP or GISP). The magnitude of the $\delta^{18} \mathrm{O}$ shifts associated with ACE 1 and 2 are also similar to those recorded in Greenland for the $11.4 \mathrm{ka}, 9.3 \mathrm{ka}$ and $8.2 \mathrm{ka}$ events, which all see shifts of $\sim 1.5$ to $2 \%{ }^{28}$ (Figure 4 and 5). In Greenland this magnitude of isotopic shift equates to a decadal average temperature decline of $\sim 3.3{ }^{\circ} \mathrm{C}$ for the latter event ${ }^{29}$.

Our isotope-based estimates of temperature change for ACE 1 and 2 of $\sim 10^{0} \mathrm{C}$ and $4^{0} \mathrm{C}$ respectively (Supplementary section 7) are greater than those estimated from the Greenland 
record. This is consistent with the widely acknowledged observation that temperature changes of the same magnitude are more muted in carbonate isotopic records than those of the ice $\operatorname{cores}^{30}$. They are also greater than the C-IT reconstructions which reflects CI-T's providing mean summer temperature estimates, whilst $\delta^{18} \mathrm{O}$ are closer to mean annual temperatures ${ }^{31}$. This implies that the ACE 1 and 2 temperature shifts were characterised by cooling in both summer and mean annual temperatures. Furthermore, the climatic cooling seen in ACE 1 and 2 can be considered of comparable or greater magnitude than that associated with the $8.2 \mathrm{ka}$ event (Figure 4 and 6). They are also associated with low percentages of Betula, which in the case of ACE 2 leads to a pause in the early Holocene Betula rise, coupled with increases in open ground taxa and/or indicators of landscape instability ${ }^{30}$ (Figure 5). All of this suggest that the ACE's are significant and extreme cooling events, with perhaps the greatest impact on winter temperatures.

\section{Discussion - The nature of hunter-gatherer adaptation during the early Holocene at Star Carr}

Star Carr represents some of the earliest evidence for postglacial re-occupation of the British Isles and highlights the rapidity with which humans returned to the region after the onset of the current interglacial. Despite an ostensibly temperate interglacial landscape, the environment that these hunter-gatherer communities occupied was dominated by climatic instability as ACEs changed both the climate and the environment of the region for many generations. These ACEs caused cooling of several degrees for $>100$ years and caused a pause in the development of a woodland environment.

The existence of human communities in a climatically unstable time interval invites two questions. Firstly, did abrupt cooling events result in the region being abandoned by these communities? Secondly, if these communities were resilient enough to persevere in a region despite sudden cooling, did the activities and operation of these societies change or adapt? These questions can be addressed by comparing the abrupt climatic events and the detail of the Star Carr archaeological record. The first event, ACE 1, occurs close to the transition to Holocene conditions and is only associated with the first, limited occupation of the site; the brushwood, which is largely naturally occurring - having washed in or fallen from trees - with some inclusions of worked wood demonstrating small-scale human activity in the area (Figure 3). This suggests that initial climate instability represented in Palaeolake Flixton palaeoenvironmental data may have delayed more intensive occupation of the site but this cannot currently be proven. The $4^{0} \mathrm{C}$ annual cooling of ACE2, implied from isotopic analysis, is as extreme as other events in the early Holocene ${ }^{26}$ (Figure 6). ACE 2 is expressed clearly in core B, and when combined with C-IT and pollen analyses, show that cooling temperatures also coincide with an increase in shrub and herb taxa and a delay in the transition into a tree-dominated landscape (Figure 5). Comparison between the timing and structure of ACE 2 and the chronology of human activity allows us to make three important observations in relation to the above questions.

Firstly, there is no hiatus in occupation during the climatic cooling of ACE 2 (Figure 4). The evidence for this primarily comes from the detrital wood scatter, a large accumulation of 
wood, about half of which is made up of wood-working debris (Supplementary Figure 6). Within the wood scatter animal bones have also been deposited. One of the earliest deposits is an elk cranium which was placed there at the start of the detrital wood sequence. This has clear parallels with deposition of bundles of elk bones into a kettle hole at Lundy Mose; the earliest Mesolithic date in Denmark ${ }^{32}$. At Star Carr, the detrital wood scatter continued to accumulate for several centuries, with animal remains, barbed points, antler headdresses/masks and utilised flint blades deposited. Of these, the most remarkable is the partially articulated remains of at least two red deer and two antler headdresses/masks which were deposited around an opening in the wood scatter. These activities are also consistent with the early phases of dryland structure construction (Figure 4).

The second point is that ACE 2 triggers no change or adaptation in human activity. Whilst it is impossible to be certain whether the earliest occupation at Star Carr pre-dated the onset of ACE 2, our chronologies indicate that there is a $65 \%$ probability that this was the case. The accumulation of brushwood (and its associated artefacts) and the detrital wood scatter both probably continued beyond ACE 2 (97\% and 77\% probability respectively). After ACE 2 the population of Star Carr continued to stabilise the lake edge using worked wood, as evidenced by the three wooden platforms (Supplementary Figure 4 and 6). These are composed of larger pieces of wood and with more structure (thus termed 'platforms') than the detrital wood scatter. However, the construction of these platforms is coincidental with the shift in local environment to a shallower and more extensive reed swamp allied to the expansion of tree pollen in the palaeoenvironmental records, rather than any ACE. The construction of more substantial wooden structures, thus, appears to result from a desire to maintain access to the lake, due to local lake-level changes, and enabled by the availability of a greater number of large trees. Despite these changes, the communities continued to deposit faunal remains and artefacts into the lake edge. This is particularly evident in Clark's area, dating to after ACE 2 (Figure 4), where large quantities of faunal remains, headdresses/masks and barbed points have been excavated.

Finally, the abandonment of platform construction and a shift to more sporadic activity across the site is coincident with the transition from the reed swamp environment to a fen carr setting. Therefore, the wetland environment resources that were provided by that ecosystem and the main focus of human activity were lost, leading to the abandonment of the site (Figure 4; Supplementary data 3, Supplementary Figure 5). Therefore, it is important to highlight that whilst the populations at Star Carr were resilient to abrupt cooling events, the major changes in activity at the site are coincident with intrinsic changes in local environmental ecological conditions and not to external climate drivers.

The populations whose presence is recorded in the Palaeolake Flixton region were some of the earliest postglacial re-colonizers of Northwest Europe ${ }^{19}$. Therefore, it may be logical to assume that such societies would be highly susceptible to ACEs, given some arguments for the impact of the $8.2 \mathrm{ka}$ event on hunter-gatherer populations ${ }^{7,8}$. However, this study highlights that there is far greater complexity to the story. The slightly more significant cooling of ACE 1 may be a limiting factor in the onset of the more intensive occupation of 
1 Star Carr, while not causing complete lack of activity of the region. ACE 2 by contrast does not appear to lead to any substantial impact on lifeways. It is possible that once established, the Star Carr community were buffered from the cooling effects of ACE 2 by continued access to a range of resources, such as red deer, which are unlikely to have been adversely affected by the changes in climate and environment recorded here.

7

8

\section{Implications}

Star Carr is almost uniquely positioned to contribute to the debates surrounding the role of abrupt climate change in the development and activity of early Holocene populations. Many studies have considered the role of the $8.2 \mathrm{ka}$ event on Mesolithic communities of northern Europe. Whilst occupation at Star Carr occurred several millennia prior to this well-defined event it is important to highlight that the magnitude of the ACEs recorded in the isotopic and chironomid records at Star Carr are as large as, and in most cases larger than, those associated with the $8.2 \mathrm{ka}$ event in other British lake sequences. Furthermore, the length of time that ACE 1 and 2 persisted for, $c a 100$ years, also makes them of comparable duration to the 8.2 ka event. The Star Carr community were clearly able to cope with this level of abrupt climate change, as not only did they continue to occupy the region despite the occurrence of ACE 2 but their activities, lake-edge occupation and platform construction/usage, continued with negligible evidence for climatically-induced change. Whilst much debate focusses on whether ACEs in the early Holocene of Northwest Europe caused large-scale population crashes, this study shows that when a high-precision archaeological chronology can be directly compared with a local climate record, hunter-gatherer populations can show a high degree of resilience to abrupt climate forcing. Thus when considering the impact of unstable early Holocene climates on hunter-gatherer populations in northwest Europe, the evidence from Star Carr indicates continuity and resilience throughout at least one ACE event.

Whilst the Star Carr dataset indicates a population with high resilience to an $8.2 \mathrm{ka}-\mathrm{like}$ ACE it is probable that the magnitude and duration of the climatic event are only two of a number of factors that dictate whether societies respond to climate forcing. Both ACE 1 and 2 occur in the very earliest Holocene and impacted upon a society living in a relatively open landscape. Whilst this study demonstrates that vegetation does respond to ACEs, the overall characteristics of the landscape, a mosaic of open grassland with areas of shrub and woodland, is maintained throughout. The $8.2 \mathrm{ka}$ event occurs after closed woodland has established itself across much of the British Isles and may lead to opening up of woodland alongside a reduction in thermophilous tax ${ }^{33}$. Therefore, it is possible that the $8.2 \mathrm{ka}$ event may have had a different impact on the nature of resources, and by extension postglacial societies, than earlier ACEs did. It is important to state, therefore, that the resilience of early populations may change through time both in relation to the impact of ACEs on particular ecological/landscape characteristics (and concomitant effect on resources) and the forms of activity and practices of the early societies involved. The adoption of the site-specific approach presented here, has allowed the specific human/climate interaction Holocene to be investigated. It is important for future research on this topic that more high resolution sitebased studies are added to the record of hunter-gatherer archaeology to refine the evidence 
1 from broader regional studies. This is particularly relevant as the pattern of human/climate 2 interaction that is seen at one site, may not be replicated at others. The ability to examine

3 many individual sites across a region with similar levels of resolution is necessary to test for 4 differences between communities and ecological settings, and avoid missing important detail 5 that allow us to understand the drivers behind both resilience and susceptibility to climate 6 change.

\section{Methods}

\section{A. Methods employed on site at Star Carr}

\section{A1. Archaeological excavations}

Each excavation context was given a unique number. Detailed sediment descriptions were undertaken of all contexts encountered, and logged on a pro forma context record sheet. Mineral sediments were described by principal grain size (gravel, coarse sand, fine sand, silt and clay, or combinations thereof), sorting (well sorted to poorly sorted) and inclusions (material forming less than $10 \%$ of the deposit), following the Museum of London Archaeology Service (MoLAS) handbook. From 2010 the recording of the wetland deposits followed a simplified, longhand version of the Troels-Smith method ${ }^{34}$. All cut features were recorded in plan, half sectioned, and the section hand drawn at an appropriate scale. Plans were drawn in relation to planning points that were recorded three dimensionally using the total station. Likewise, all section datum points were recorded using the total station. Registers for contexts, drawings, samples, photographs, levels and recorded finds were kept on recording sheets. All records were entered into excel spreadsheets during each season and checked in post-excavation.

\section{A2. Macrofossil analysis}

Macrofossil analysis was undertaken on samples from three locations across the site in order to establish the character of the local environment and the wetland context within which human activity took place. In each case contiguous sequences of samples (25-50mm thick) were taken through the complete sequence of detrital muds and peat at the lake edge, spanning the entire stratigraphic range of the archaeological material. These were subsampled $(50 \mathrm{ml}$ ), and disaggregated by boiling in $10 \%$ sodium hydroxide. The material was then washed through sieves ( $2 \mathrm{~mm}-125$ microns) and examined under a Nikon SMZ45T stereo microscope at $\mathrm{x} 10-\mathrm{x} 40$ magnification. Material from the $2 \mathrm{~mm}-250$ micron sieves that could be identified to a taxonomic level (typically seeds, fruits, nuts/nutlets, oospores, and catkin bud scales) were counted, with the exception of moss stems and water-lily seed fragments (see below). The results were quantified and displayed using the $\mathrm{C} 2$ software $^{35}$. Small fragments of water-lily seed, indeterminate aquatic plant tissue, fern sporangia and any highly fragmented but identifiable plant macrofossils, were quantified on a scale of relative abundance $(0=$ absent, $1=$ sparse, $2=$ present, $3=$ =abundant $)$. 
1 Wood identifications were carried out by taking thin sections from the radial, transverse and

2 transversal planes using a sharp razor blade, which were mounted on slides and examined 3 under $\mathrm{x} 10$-x30 magnification.

4

5

6

7

8

9

10

11

12

13

14

15

16

\section{B. The lacustrine record}

\section{B1. Core profiles}

The stratigraphy of the climatic events that occurred after the Last Glacial Maximum was reconstructed through a detailed survey of the deposits of Palaeolake Flixton ${ }^{21}$ The core stratigraphies were analysed for carbon content and CI-T, oxygen and carbon isotopes, tephrochronology, pollen, and radiocarbon dating across the whole profiles of cores B and $\mathrm{C}^{21}$ (see Supplementary information). High-resolution analyses then focussed on the early Holocene and late Loch Lomond stadial sections. The age model of this record is constrained by six radiocarbon ages, the presence of the Vedde Ash (at 523-522 $\mathrm{cm}$ below surface in core C) and correlation of four key biostratigraphic markers within previously well dated Star Carr records (Supplementary Table 1). This model is defined by the OxCal CQL2 code, star_carr_climate_B_C_to_Vedde_final.oxcal ${ }^{2}$; and summarised in supplementary Figures 13-15; and Supplementary Tables 2-4. The Younger Dryas/Holocene transition history recorded in this sequence is broadly synchronous with the Greenland ice cores.

\section{B2. Pollen}

1cc pollen samples were extracted at $8 \mathrm{~cm}$ resolution between $509-333 \mathrm{~cm}$ and $4 \mathrm{~cm}$ between $301-205 \mathrm{~cm}$ in core B; and $12 \mathrm{~cm}$ between $525-381 \mathrm{~cm}$ and $4 \mathrm{~cm}$ between $381-281 \mathrm{~cm}$ in core C, down to the Vedde $\mathrm{Ash}^{21}$ following standard procedures, including treatment with HCL, acetolysis and Hydrofluoric Acid. Residues were mounted in Glycerine Jelly without staining. A minimum count of 300 total land pollen (TLP) grains was obtained for all levels using an Olympus CX41 binocular microscope (400x), aided by reference collections ${ }^{36}$. All land pollen, aquatic pollen and pteridophyte spores are presented as percentages of TLP. Pollen diagrams were constructed using $\mathrm{C}^{35}$ with diagram zonation, using untransformed TLP pollen data cut off at $2 \%$, assisted by CONISS ${ }^{37}$. All micro-charcoal greater than $5 \mu \mathrm{m}$ was also counted.

\section{B3. Chironomids}

Chironomid larvae head capsules from the 3rd and 4th instars (developmental stages) are typically preserved as fossils, are extracted and typically identified to genus or species morphotype. They are excellent indicators of temperature as this influences their emergence, flight, swarming, maturing of eggs and sexual activity. Samples for chironomids $\left(\sim 2 \mathrm{~cm}^{3}\right.$ wet weight) were disaggregated in $10 \% \mathrm{KOH}$ and sieved to $<90 \mu \mathrm{m}$, whilst retaining all head capsules. Head capsules were picked and mounted on microscope slides in Hydro-Matrix, and identified under x 400 magnification. Subfossil chironomid taxonomy is based on Brooks et $\mathrm{al}^{38} .122$ chironomid samples were analysed from cores B and C covering the Early Holocene and Loch Lomond stadial transition. Data were analysed using a transfer functions for summer temperatures developed from Norwegian lakes ${ }^{39}$. 


\section{B4. Isotopes}

$\delta^{18} \mathrm{O}$ of lacustrine carbonate is primarily controlled by the temperature at which carbonate mineralisation occurs and the $\delta^{18} \mathrm{O}$ value of the lake water. The latter is determined by the $\delta^{18} \mathrm{O}$ of rainfall, which is controlled by $\sim$ air temperature, rainfall amount, seasonality and distance from the moisture source ${ }^{40}$. Stable carbon isotopic ratios $\left(\delta^{13} \mathrm{C}\right)$ are determined by the amount of organic input and productivity in a lake, and, at this site, in-wash of minerogenic carbonate from the surrounding chalk. The latter is an indicator of a detrital component and we have excluded any paired isotope samples with a $\delta^{13} \mathrm{C}$ value above 2 , as this is close to the bedrock value. 200 isotope samples were taken from the Star Carr core B over between 2-5 m depth; approximately 20-23 m OD, with the Early Holocene (2-3 m) analysed in greatest detail. 26 samples were taken from core C 2.83-4 m depth in core (c. 21 to $19.83 \mathrm{~m} \mathrm{OD})$. Carbonates were sampled at $10 \mathrm{~mm}$, disaggregated in sodium hexametaphosphate and sieved over a 63 micron mesh with the $>63$ micron fraction used for further analyses. Samples were treated with hydrogen peroxide, weighed in a microbalance and isotopes measured on the liberated fraction of $\mathrm{CO}_{2}$ after reaction with phosphoric acid at $90^{\circ} \mathrm{C}$, and are reported with reference to VPDB standard.

\section{B5. Sampling for Radiocarbon Dating}

$1 \mathrm{~cm}$ wide sections were contiguously cut from the core B, then sub-sampled by taking $2.5 \mathrm{~cm}$ $\mathrm{x} 2.5 \mathrm{~cm} \times 1 \mathrm{~cm}$ thick blocks from the central part of the disc. The outer edges of each subsample were cleaned and stored at $4^{\circ} \mathrm{C}$ prior to sieving.

Samples were sieved over a 200 micron mesh and macrofossil material was cold-stored in glass vials with acidified water. Terrestrial macrofossil remains were picked using a low powered binocular microscope (10-40x magnification) and identified using reference collections and manuals ${ }^{41}$.

To avoid possible hard-water error from a site on a carbonate bedrock, sampling was restricted to what were thought to be terrestrial plant macrofossils. Where possible, macrofossils of leaves, fruit, bud and catkin scales from Betula sp. and Populus sp. were selected. These were sparse, thus, Carex sp. seeds were also isolated. In some cases, small fragments of what were thought to be sedge remains had to be bulked together to provide sufficient material. Given some enriched $\delta^{13} \mathrm{C}$ values (SI), unidentifiable remains of freshwater plants appear to have been incorporated in some samples. Where individual centimetres could not provide sufficient material for dating, macrofossils from adjacent slices were amalgamated. Samples were then analysed at the University of Oxford Radiocarbon Accelerator Unit.

\section{Radiocarbon dating, Bayesian chronological modelling}

\section{C1. The archaeological and palaeoenvironmental model}

200 radiocarbon measurements are available from archaeological and lake-edge environmental deposits ${ }^{25}$. A complex Bayesian chronological model has been constructed to estimate the dates of different aspects of human activity at Star Carr and the contemporary 
1 local environment at the lake-edge. The dating evidence and chronological model is fully defined by the OxCal CQL2 code files provided here (the principal part of the model is defined by "star_carr_combined_all_v3.oxcal", with additional parameters calculated by "star_carr_combined_all_v3_additional.oxcal"). The basic principle behind this model is that relationships between radiocarbon dates associated with human activity and radiocarbon dates associated with environmental sequences and events are implemented together, and then cross reference is made to these constrained distributions in considering the chronologies of the human activity and lake edge environment respectively. For example, the dates on artefacts from the detrital wood scatter from Trench 34 were recovered from fine detrital mud that must post-date the start of organic sedimentation in the adjacent environmental profile 3178. This date estimate also, however, provides information on when environmental Zone 1 began in a specific part of the lake edge. The parameter onset organics 3178 therefore crossrefers to both the archaeological and environmental parts of the model and is constrained by relationships of both types.

\section{C2. Radiocarbon dating}

Establishing a robust chronology for the climate record in the vicinity of Star Carr has been challenging because of the poor preservation of macrofossils from terrestrial plants within the studied sediments. This constrained both the number of samples that could be dated, and the character of the material that was isolated for dating. This analysis covers the early Holocene part of core B (above $298-300 \mathrm{~cm}$ ) and the upper part of core C (above $522-3 \mathrm{~cm}$, the depth marking the Vedde $a h^{21}$ ). Six radiocarbon measurements on waterlogged plant macrofossils were obtained on the upper part of core B by the Oxford Radiocarbon Accelerator Unit in 2015. All samples were pretreated using acid-base-acid, graphitised and dated by $\mathrm{AMS}^{42}$ and they are reported in Supplementary section 7.

The model for the chronology of the lacustrine sediments is based on two inter-linked agedepth models for the upper parts of cores B and C. Both are poisson process depositional models $^{43}$ implemented using a variable rigidity parameter and the general outlier model proposed $\mathrm{in}^{44}$. Dates have been interpolated every centimetre. The age model of this record is constrained by six radiocarbon ages, the presence of the Vedde Ash (at 523-522 $\mathrm{cm}$ below surface in core C) and correlation of four key biostratigraphic markers within previously well dated Star Carr records (Supplementary data 6; Supplementary Tables 3 and 4, Supplementary Figure 14). This model is defined by the OxCal CQL2 code, provided as supplementary information (Supplementary Figures 13-15; Supplementary Tables 2-4; data file star_carr_climate_B_C_to_Vedde_final.oxcal ${ }^{24}$ ). The Younger Dryas/Holocene transition history recorded in this sequence is broadly synchronous with the Greenland ice cores.

Core B has six radiocarbon ages from five depths in the core. Mixed-source calibration (see above) has been used for the lowest three measurements, including the two from replicate macrofossil samples at a depth of $285 \mathrm{~cm}$. Each result at this level has first been calibrated using the specific calibration curve derived from the mixing model, and then the calibrated dates combined to provide an estimate for the date of sediment deposition at this depth 
1 (Rumex_peak). The upper three measurements have been calibrated using a fully terrestrial

2 calibration curve ${ }^{45}$.

3 Core $\mathrm{C}$ contains the Vedde Ash at a depth of $522-3 \mathrm{~cm}$. We recalculated the combined age4 depth model which includes the integrated age of this tephra ${ }^{46}$ at a resolution of 1 year to 5 ensure compatibility with the archaeological and lake-edge palaeoenvironmental model 6 (Bronk_Ramsey_tephra_model.oxcal), and imported the resultant posterior distribution for 7 the Vedde ash as a prior distribution at the relevant depth in Core C. A potential change in 8 deposition rate was modelled at the transition from clay to marl.

9 The two age-depth models for Cores $\mathrm{B}$ and $\mathrm{C}$ were then inter-related using a series of 10 biostratigraphic tie points (Supplementary Figure 14), and Core B was similarly related to 11 lake-edge monolith M1 from the archaeological investigations, that is built into the overall 12 age model for Star Carr archaeology ${ }^{25,47}$. Appropriate correlation points were determined by observations of similar trends in each of the pollen diagrams. Pollen taxa that relate to very local influence were not selected, and neither were taxa that were found in very low abundance, thus ensuring that the correlation is as robust as possible.

\section{References}

18

1. Flohr, P., Fleitmann, D., Matthews, R., Matthews, W. \& Black, S. Evidence of resilience to 20 past climate change in Southwest Asia: early farming communities and the 9.2 and $8.2 \mathrm{Ka}$ Events. Quat. Sci. Rev. 136, 23-39 (2016).

2. de Pablo, J. F. L. \& Jochim, M. A. The impact of the 8,200 cal BP climatic event on human mobility strategies during the Iberian late Mesolithic. J. Anthropol. Res. 66, 39-68 (2010).

3. Bicho, N., Umbelino, C., Detry, C. \& Pereira, T. The Emergence of Muge Mesolithic Shell Middens in Central Portugal and the $8200 \mathrm{Cal}$ Yr BP Cold Event. J. Island \& Coastal Archaeol. 5, 86-104 (2010).

28 4. Climate and Cultural Change in Prehistoric Europe and the Near East (eds Biehl P. 29 F. \& Nieuwenhuyse O. P.) (State Univ. of New York Press, 2016).

30 5. Crombé P. \& Robinson, E. Human resilience to Lateglacial climate and environmental change in the Scheldt basin (NW Belgium). Quat. International 428, 50-63 (2017). 6. González-Sampériz, P. et al. Patterns of Human Occupation during the Early Holocene in the Central Ebro Basin (NE Spain) in Response to the 8.2 Ka Climatic Event. Quat. Res. 71 (2), 121-32 (2009).

7. Wicks K. \& Mithen S. The impact of the abrupt $8.2 \mathrm{ka}$ cold event on the Mesolithic population of western Scotland: a Bayesian chronological analysis using 'activity events' as a population proxy. J. Archeol. Sci. 45, 240-269 (2014).

38 8. Waddington C. \& Wicks, K. Resilience or Wipe out? Evaluating the convergent impacts of the $8.2 \mathrm{ka}$ event and Storegga Tsunami on the Mesolithic of Northeast Britain. J. Archeol. Sci.

40 Reports 14, 692-714 (2017).

41 9. Griffiths, S. \& Robinson, E. The 8.2 Ka BP Holocene Climate Change Event and Human 42 Population Resilience in Northwest Atlantic Europe, Quat. International (2017) 
10. Woodman, P. C. Challenging times: reviewing Irish Mesolithic chronologies. Chronology and Evolution within the Mesolithic of North-West Europe (eds Crombé, P., Van Strydonck, M., Boudin, M. \& Bats, M.)195-215 (Camb. Scholars Publishing 2009) 11. Mayewski P. et al. Holocene climate variability. Quat. Res. 62, 243-255 (2004).

12. Daley T. J. et al. The $8200 \mathrm{yr}$ BP cold event in stable isotope records from the North Atlantic region. Glob. Planet Chang. 79, 288-302 (2011).

13. Contreras D. A. \& Meadows J. Summed radiocarbon calibrations as a population proxy: a critical evaluation using a realistic simulation approach. J Archeol Sci 52, 591-608 (2014). 14. Edwards, K. J., Langdon, P. G., \& Sugden, H. Separating climatic and possible human impacts in the early Holocene: biotic response around the time of the 8200 cal. yr BP event. J. Quat. Sci. 22, 77-84 (2007).

15. Rasmussen S. O. et al. A stratigraphic framework for abrupt climatic changes during the Last Glacial period based on three synchronized Greenland ice-core records: refining and extending the INTIMATE event stratigraphy. Quat. Sci. Rev. 106, 14-28 (2014).

16. Clark J. G. D. Excavations at Star Carr: an early Mesolithic site at Seamer near Scarborough, Yorkshire (Camb. Univ. Press, 1954).

17. Star Carr in context: new archaeological and palaeoecological investigations at the Early Mesolithic site of Star Carr, North Yorkshire (eds Mellars P. \& Dark P.) (McDonald Institute for Archaeological Research, 1998). 18. Conneller C., Milner N., Taylor B. \& Taylor M. Substantial settlement in the European Early Mesolithic: new research at Star Carr. Antiquity 86, 1004-1020 (2012) .

19. Conneller C., Bayliss A., Milner N. \& Taylor B. The resettlement of the British landscape: towards a chronology of Early Mesolithic lithic assemblage types. Internet Arch. 42, (2016).

20. Star Carr: Life in Britain after the Ice Age (eds Milner N., Taylor B., Conneller C. \& Schadla-Hall R. T.) (Council for British Archaeology, 2013).

21. Palmer A. P. et al. The evolution of Palaeolake Flixton and the environmental context of Star Carr, NE. Yorkshire: stratigraphy and sedimentology of the Last Glacial-Interglacial Transition (LGIT) lacustrine sequences. Proc. Geol. Assoc. 126, 50-59 (2015). 22. Conneller C. \& Schadla-Hall R. T. Beyond Star Carr: The Vale of Pickering in the tenth millennium BP. Proc. Prehis. Soc. 69, 85-105 (2003).

23. Little A et al. Technological Analysis of the World's Earliest Shamanic Costume: A Multi-Scalar, Experimental Study of a Red Deer Headdress from the Early Holocene Site of Star Carr, North Yorkshire, UK. PLoS ONE 11 (2016).

24. Bronk Ramsey, C. Bayesian analysis of radiocarbon dates. Radiocarbon 51, 337-360, (2009).

25. Star Carr, Volume 2: studies in technology, subsistence and environment (eds Milner N.,

Conneller C. \& Taylor B.) (White Rose University Press, York, in press) (doi: 10.22599/book2).

26. Marshall J.D. et al. Terrestrial impact of abrupt changes in the North Atlantic thermohaline circulation: early Holocene, UK. Geology 35, 639-642 (2007). 75-92 (2016). 
28. Rasmussen, S. O., Vinther, B. M., Clausen, H. B. \& Andersen, K. K. Early Holocene climate oscillations recorded in three Greenland ice cores. Quat. Sci. Rev. 26, 1907-1914, (2007).

29. Kobashi, T., Severinghaus, J.P., Brook, E.J., Barnola, J-M. \& Grachev, A. M. Precise timing and characterization of abrupt climate change 8200 years ago from air trapped in polar ice, Quat. Sci. Reviews 26, 1212-1222 (2007).

30. Candy I. et al. Oxygen isotopic evidence for high-magnitude, abrupt climatic events during the Lateglacial Interstadial in northwest Europe: analysis of a lacustrine sequence from the site of Tirinie, Scottish Highlands. J Quat Sci 31, 607-621 (2016).

31. Candy, I., Stephens, M., Hancock, J.D.R. \& Waghorn, R.S. Palaeoenvironments of ancient human occupation: the application of oxygen and carbon isotopes to the reconstruction of Pleistocene environments. (eds Ashton, N., Lewis, S.G. \& Stringer, C.) The Ancient Human Occupation of Britain Project. Developments in Quaternary Science, 23-37 (Elsevier, 2011).

32. Jessen, C. A. et al. Early Maglemosian culture in the Preboreal landscape: archaeology and vegetation from the earliest Mesolithic site in Denmark at Lundby Mose, Sjælland. Quat. Int. 378, 73-87 (2015).

33. Holmes, J. A. et al. Lake isotope records of the 8200-year cooling event in western Ireland: Comparison with model simulations, Quat. Sci. Rev. 131, 341-349 (2016).

34. Troels-Smith J. Karakterisering af løsejordater (Characterisation of unconsolidated sediments) Danmarks Geologiske Unders $\phi$ gelse, Series IV, 3, 73 (1955).

$\begin{array}{lllllll}\text { 35. Juggins } & \text { S. } & C 2 & \text { software } & \text { version } & 7\end{array}$ https://wwwstaffnclacuk/stephenjuggins/software/C2Homehtm (2016)

36. Moore P. D., J. A. Webb \& Collinson M. E. Pollen analysis (Blackwell Scientific, London, 1991).

37. Grimm E. C. CONISS: a FORTRAN 77 program for stratigraphically constrained cluster analysis by the method of incremental sum of squares. Comp. \& Geosci. 13, 13-35 (1987).

38. Brooks S. J., Langdon P. G. \& Heiri O. The identification and use of Palaearctic Chironomidae larvae in palaeoecology. QRA Technical Guide No 10 (Quaternary Research Association, London, 2007).

39. Brooks S. J. \& Birks H. J. B. Chironomid-inferred air temperatures from late-glacial and Holocene sites in north-west Europe: progress and problems Quat. Sci. Rev. 20, 1723-1741 (2001).

40. Darling W. G. Hydrological factors in the interpretation of stable isotopic proxy data present and past: a European perspective. Quat. Sci. Rev. 23, 743-770 (2004).

41. Dickson C. A. The study of plant macrofossils in British Quaternary deposits. Studies in the Vegetation History of the British Isles (eds Walker, D. \& West, R.G.) 233-254 (Camb. Univ. Press, 1970).

42. Bronk Ramsey C., Higham T. F. G. \& Leach P. Towards high precision AMS: progress and limitations. Radiocarbon 46, 17-24 (2004).

43. Bronk Ramsey C. Deposition models for chronological Quat Sci Rev 27, $42-60$ (2008).

44. Bronk Ramsey C. Dealing with outliers and offsets in radiocarbon dating. Radiocarbon 51, 1023-1045 (2009). 
45. Reimer P. J. et al. IntCal13 and Marine13 radiocarbon age calibration curves 0-50,000 years cal BP. Radiocarbon 55, 1869-1887 (2013).

46. Bronk Ramsey C. et al. Improved age estimates for key Late Quaternary European tephra horizons in the RESET lattice. Quat. Sci. Rev. 118, 18-32 (2015).

47. Dark P. Palaeoecological investigations. Star Carr in context: new archaeological and palaeoecological investigations at the early Mesolithic site of Star Carr, North Yorkshire (eds Mellars P. \& Dark P.) 11-120 (McDonald Institute for Archaeological Research, 1998) 48. Bronk Ramsey C. OxCal ver.4.3, https://c14.arch.ox.ac.uk/oxcal/OxCal.html (2017). 49. Bedford, A., Jones, R. T., Lang, B., Brooks, S. \& Marshall, J. D. A Late-glacial chironomid record from Hawes Water, northwest England. J. Quat. Sci. 19, 281-290 (2004).

\section{Acknowledgments.}

We thank the landowners of Star Carr, English Heritage/Historic England, and Natural England for granting permission to excavate. This project has received funding from the European Research Council (ERC) under the European Union's Seventh Framework Programme (FP7/2007-2013) under grant agreement No 283938 British Academy Grants SG44333, SG-47081, and SG-50217; English Heritage/Historic England Grants 5536, 6064, 6793, 6796 and the radiocarbon dating of the site; Natural Environment Research Council Grant NE/I015191/1; and the Vale of Pickering Research Trust. RS is supported by an Early Career Fellowship from the Leverhulme Trust (ECF-2015-396). Abrook is supported by the Natural Environments Research Council, London Doctoral Training Programme.

\section{Author Contributions}

S.B., I.C., I.M., P.Lan., A.P. designed and directed the climate and environmental analysis. S.B. and A.M. analysed tephra, I.C. directed carbon and oxygen isotope analyses, these were conducted by L.D., C.D., R.K., I.M. and A.A. analysed pollen data, A.P., S.B., I.M., A.A., A.M., I.C. and P.L. analysed lake topography and sediments, B.T. analysed macrofossil data from the site, M.B. and M.T. analysed the archaeological wood and platforms. P. Lan and C.L. analysed chironomid samples, R.S. carried out the radiocarbon dating, A.B. carried out the Bayesian modelling, with assistance from I.M., S.B., A.P., A.A., C.C., B.T. P.L. and N.M. N.B. carried out the source proportion mixing model. N.M., B.T., C.C. designed and directed the archaeological excavation. NM was granted funding. S.B., I.C., A.B., P. Lan. and NM led the writing of the paper and all authors contributed to the writing, discussed the results and commented on the manuscript.

\section{Competing Financial Interests Statement}

The authors declare no competing financial interests.

\section{Data Availability Statement}

All relevant data supporting figures in the text is available in the main Supplementary Information PDF with the exception of the full OxCal codes, which have been uploaded as separate SI files and can be used to reconstruct the site age models. The specific OxCal codes for each element are highlighted in Supplementary Information section 7. 


\section{Figure Legends}

Figure 1: The context for the site: (a) Greenland ice core record of the Last Glacial to interglacial Transition, highlighting abrupt events and the timeline for archaeological occupation events; maps showing the position of Star Carr with relevance to; B) Location of the site in its European context, B1 location within North East England, B2 Sites around Palaeolake Flixton; C) borehole survey results for the Star Carr area of Palaeolake Flixton and; D) stratigraphic logs and $\mathrm{CaCO} 3$ results.

Figure 2: An antler headdress/mask from Star Carr. This was found in 2015 within Clark's area (Photo: Neil Gevaux).

Figure 3: Probability distributions of key parameters of archaeological activities at Star Carr. $O x A-3349$ is the start of burning 1,OxA-33662 is the dated timber from the eastern platform, SUERC-59177 is the bark mat, and $O x A-25240$ is the bow, derived from the model defined exactly by the $\mathrm{OxCal}^{48} \mathrm{CQL} 2$ code files provided in supplementary information (star_carr_combined_all_v3.oxcal and star_carr_combined_all_v3_additional.oxcal) all on the IntCal13 timescale ${ }^{43}$.

Figure 4: The main elements of the occupation of Star Carr against key palaeoenvironmental indicators for Palaeolake Flixton: Pollen for cores B and C, carbon and oxygen isotopes for cores $\mathrm{B}$ and $\mathrm{C}$ and Chironomid-Inferred temperatures for cores $\mathrm{B}$ and $\mathrm{C}$, all plotted against the chronologies provided by the Bayesian age model (see Supplementary data).

Figure 5: Summary pollen and isotopic results for core $B$ against depth: showing the local ecological impact of the ACE 2 event, in particular the pause in the Early Holocene Betula rise and total land pollen, and the peak in Salix and Juniperus. 
1 Figure 6: The structure of the climatic shifts for ACE 2 in comparison with other data:

2 detailing the $\delta^{18} \mathrm{O}$ and $\mathrm{C}$-IT against the same data for best record for the UK expression of the

$38.2 \mathrm{ka} \mathrm{BP}$ event in Northern England, from Hawes Water $\left(\delta^{18} \mathrm{O}^{26} ; \mathrm{C}-\mathrm{IT}^{49}\right)$, Northeast

4 England. All records have been chronologically centred on the coldest point of each profile. 

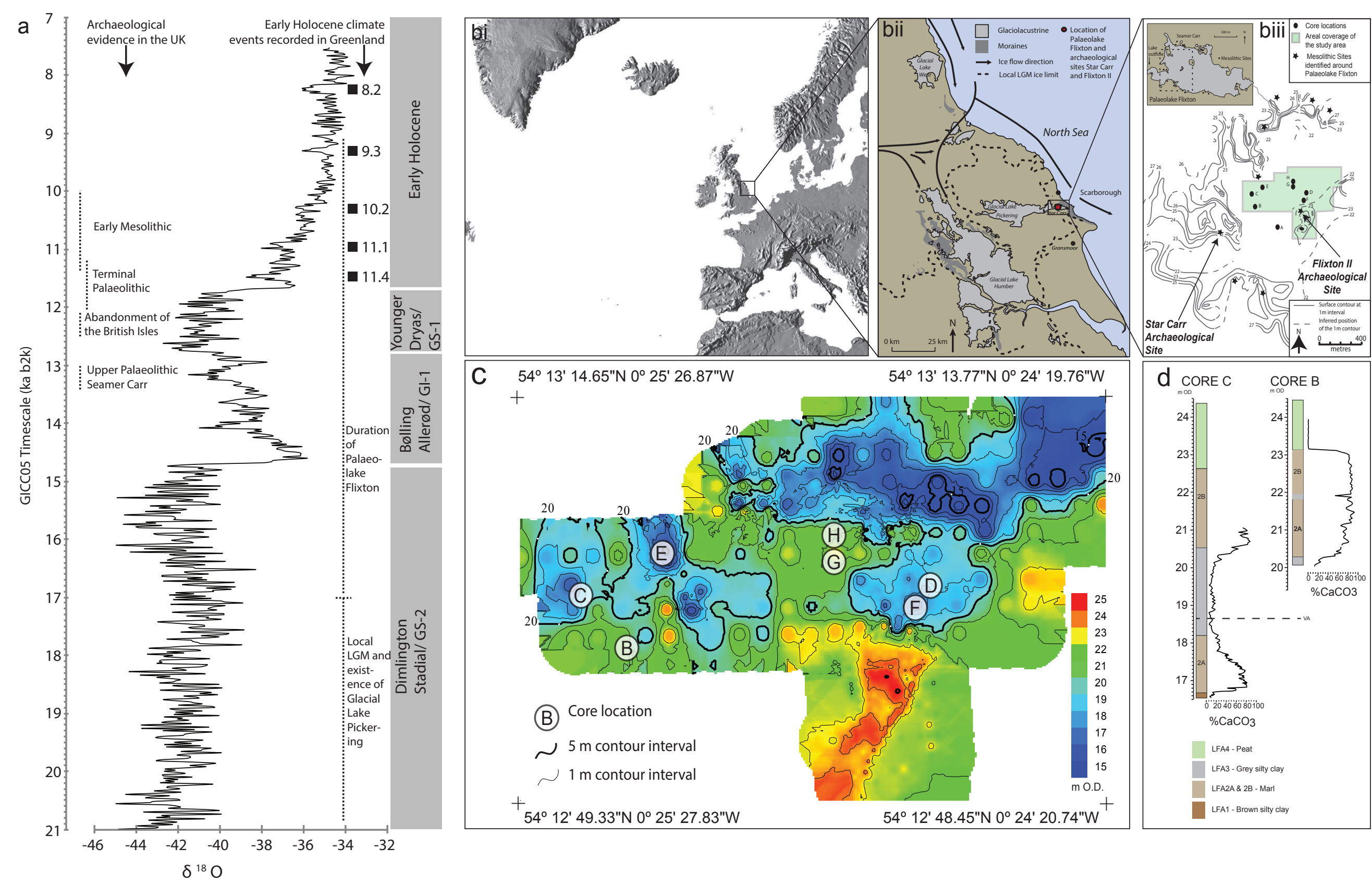

$54^{\circ} 12^{\prime} 49.33^{\prime \prime} 0^{\circ} 25^{\prime} 27.83^{\prime \prime W}$

$54^{\circ} 12^{\prime} 48.45 " \mathrm{~N}^{\circ} 24^{\prime} 20.74$ "W $^{+}$

LFA1 - Brown silty clay 


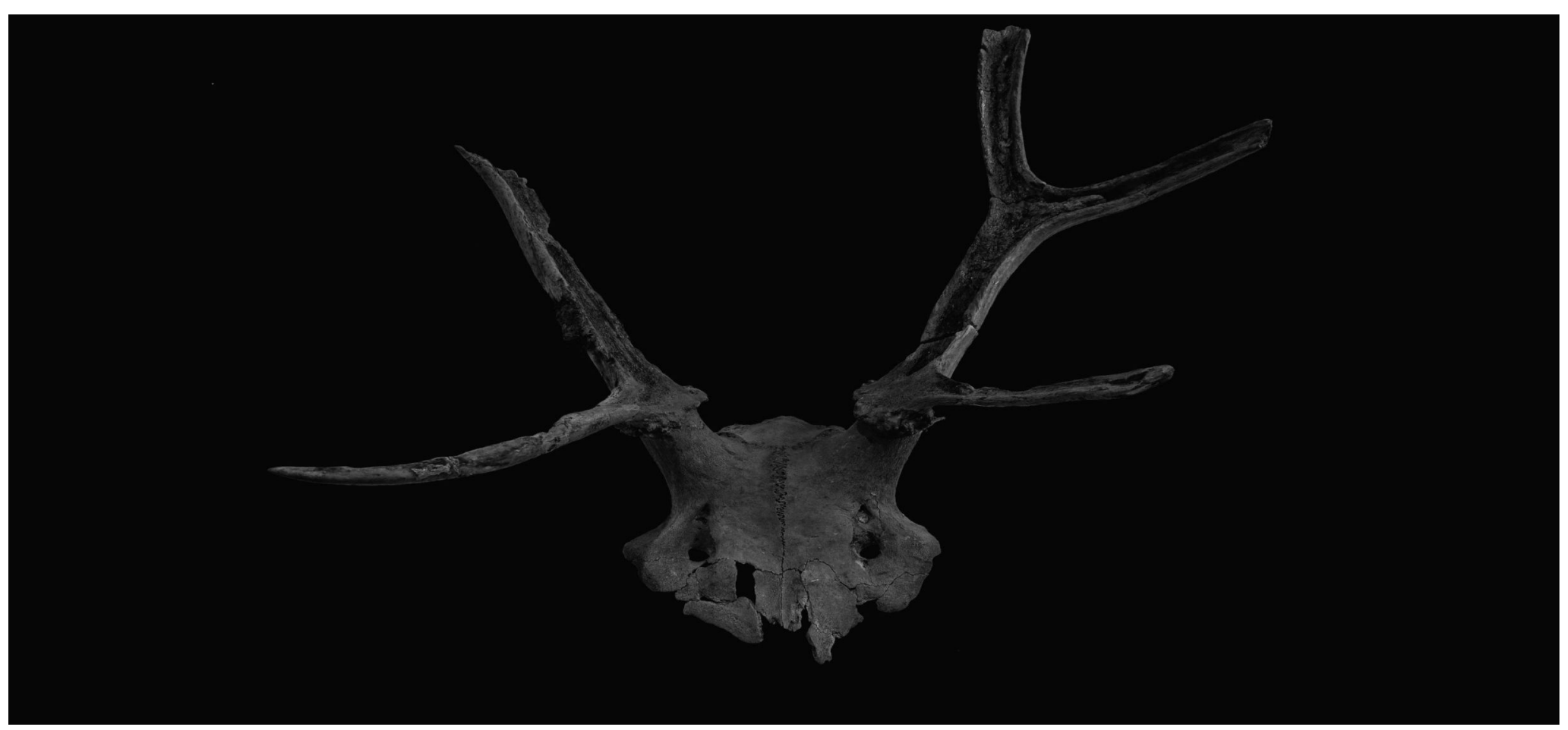




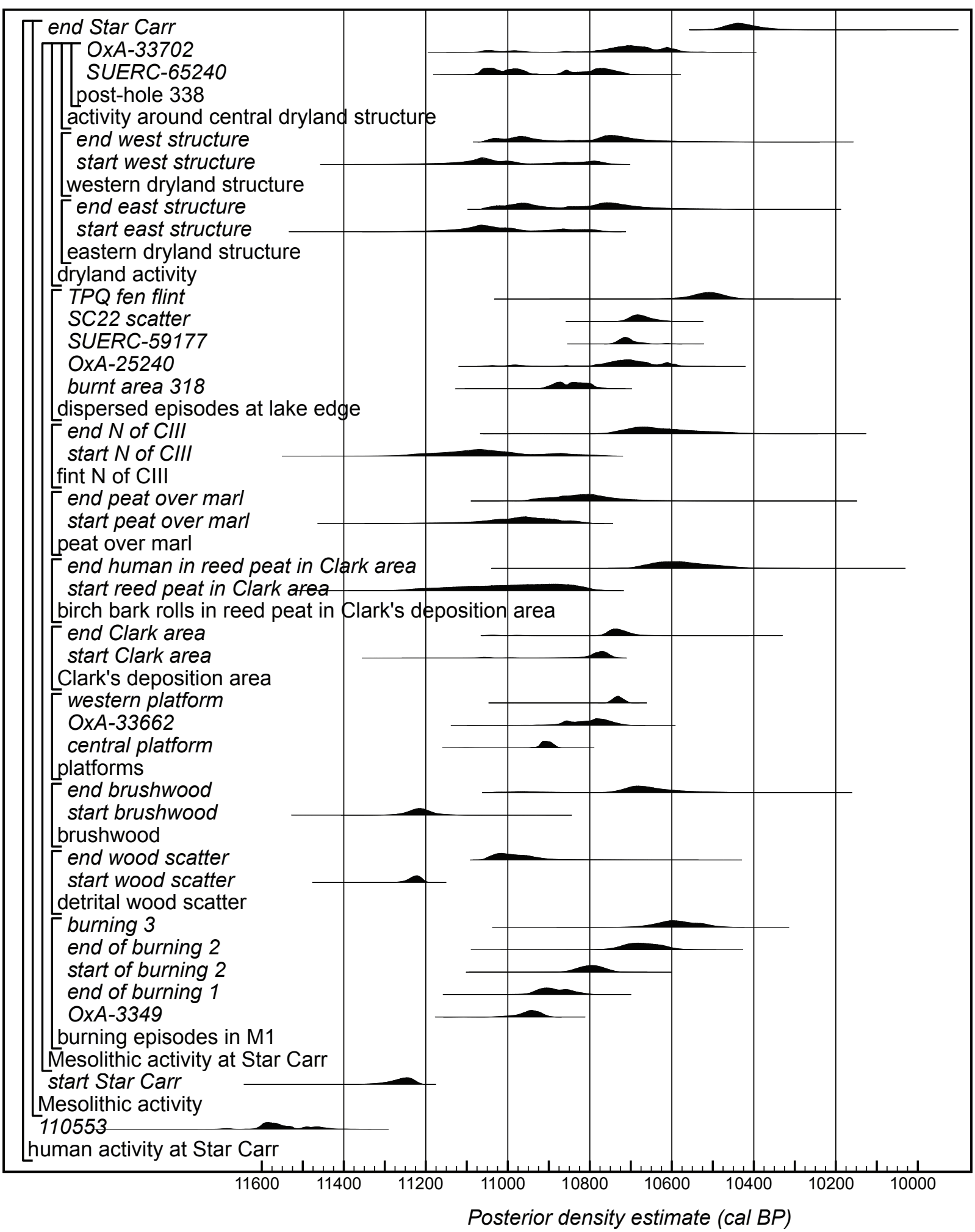


ka cal BP

$\begin{array}{llllllllllllllllllllllll}12.2 & 12.1 & 12.0 & 11.9 & 11.8 & 11.7 & 11.6 & 11.5 & 11.4 & 11.3 & 11.2 & 11.1 & 11.0 & 10.9 & 10.8 & 10.7 & 10.6 & 10.5 & 10.4 & 10.3 & 10.2 & 10.1 & 10.0 & 9.9\end{array}$

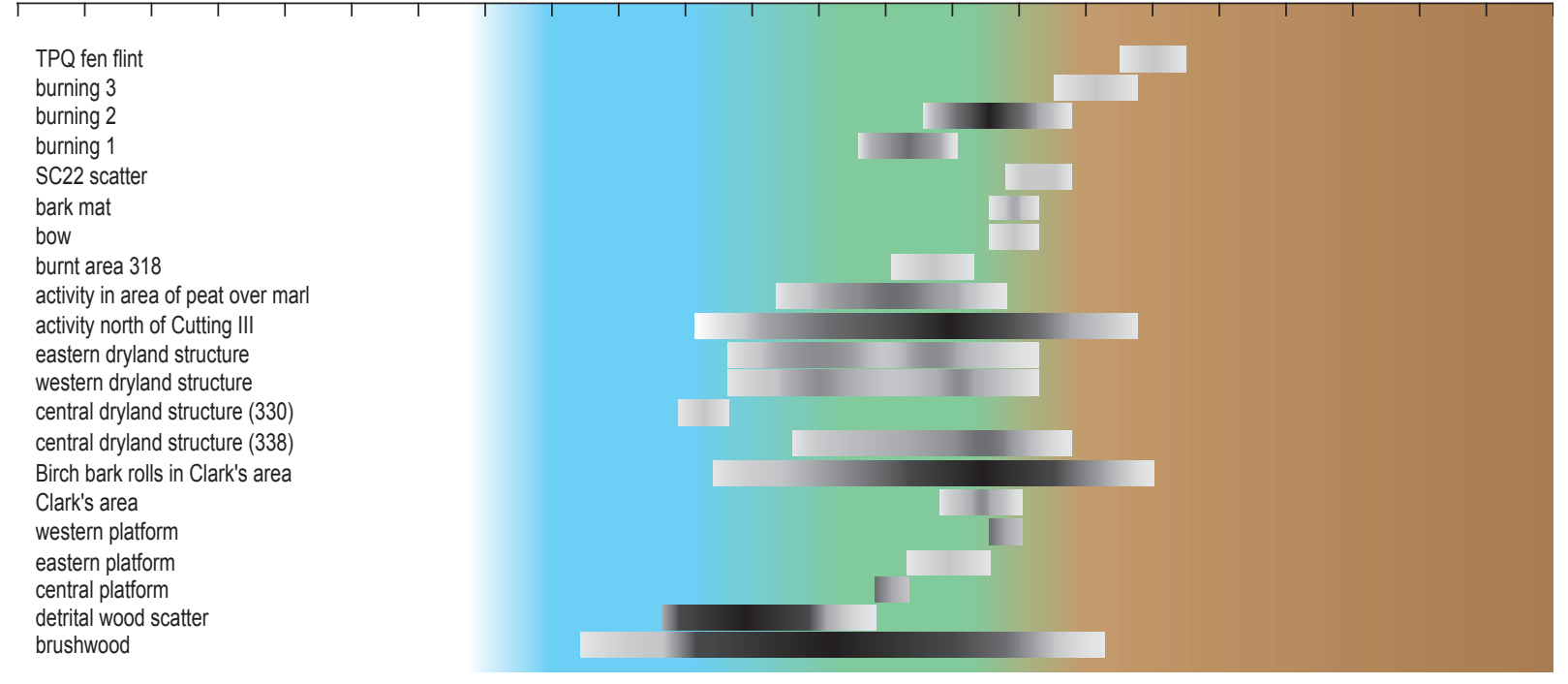

$1 \quad L_{11-25}$

$\begin{array}{ll}2 & 26-40 \\ 3 & 41-55 \\ 4 & 56-70 \\ 5 & \\ 6 & 71-85 \\ 6 & 86-100\end{array}$

Environmental Zone

Environmental Zone 2

Environmental Zone 3

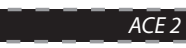

ACE 1
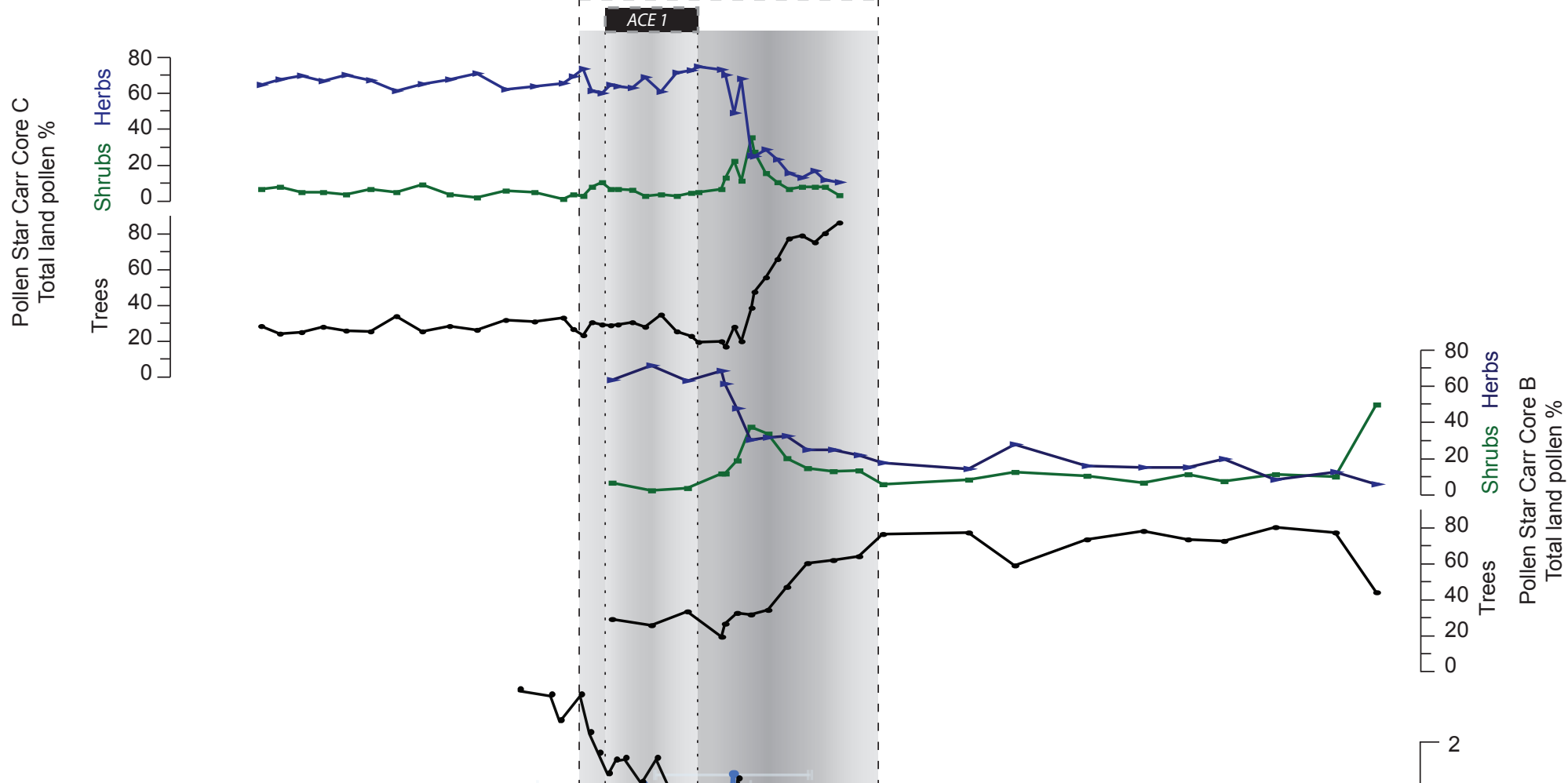

Core $B \delta^{13} \mathrm{C}$

(1)
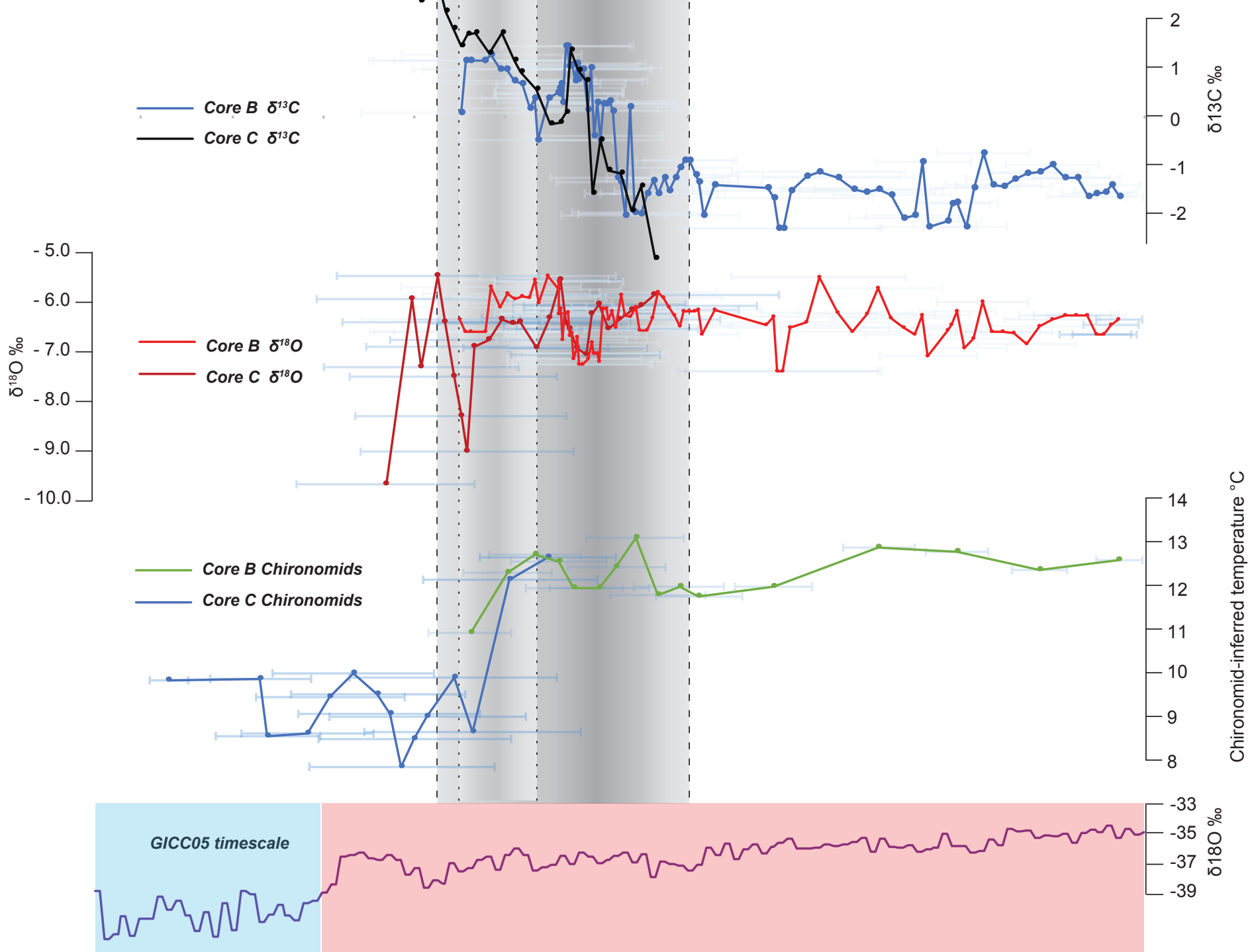

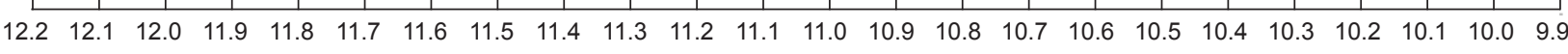




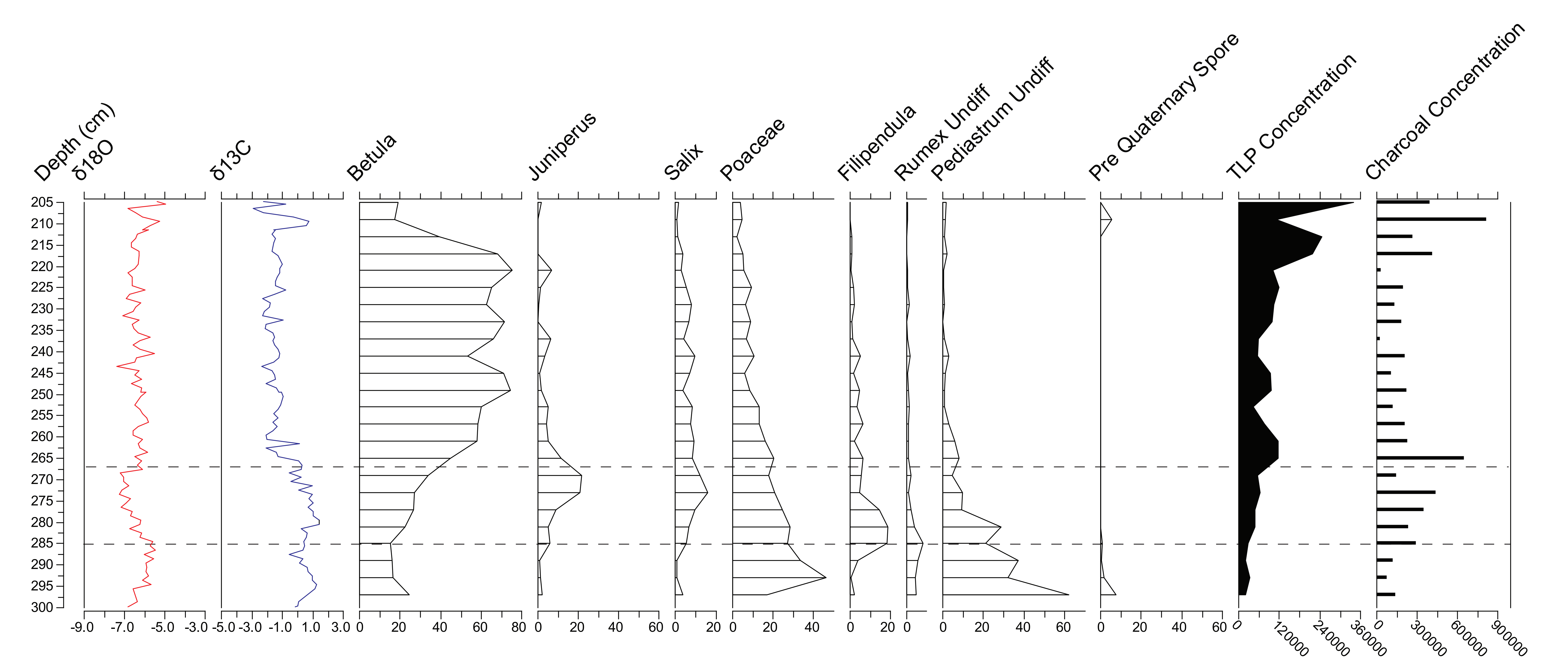




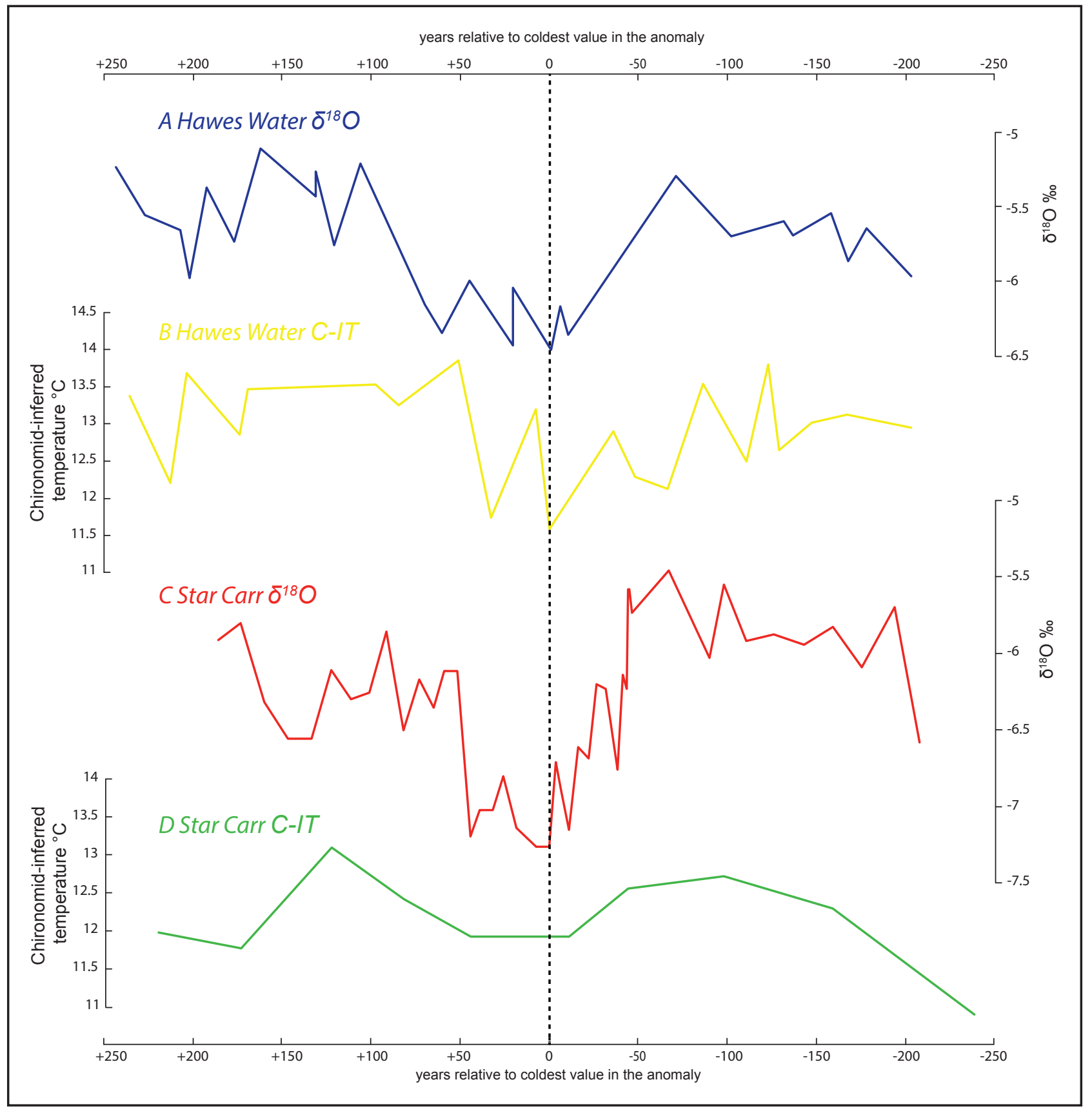

